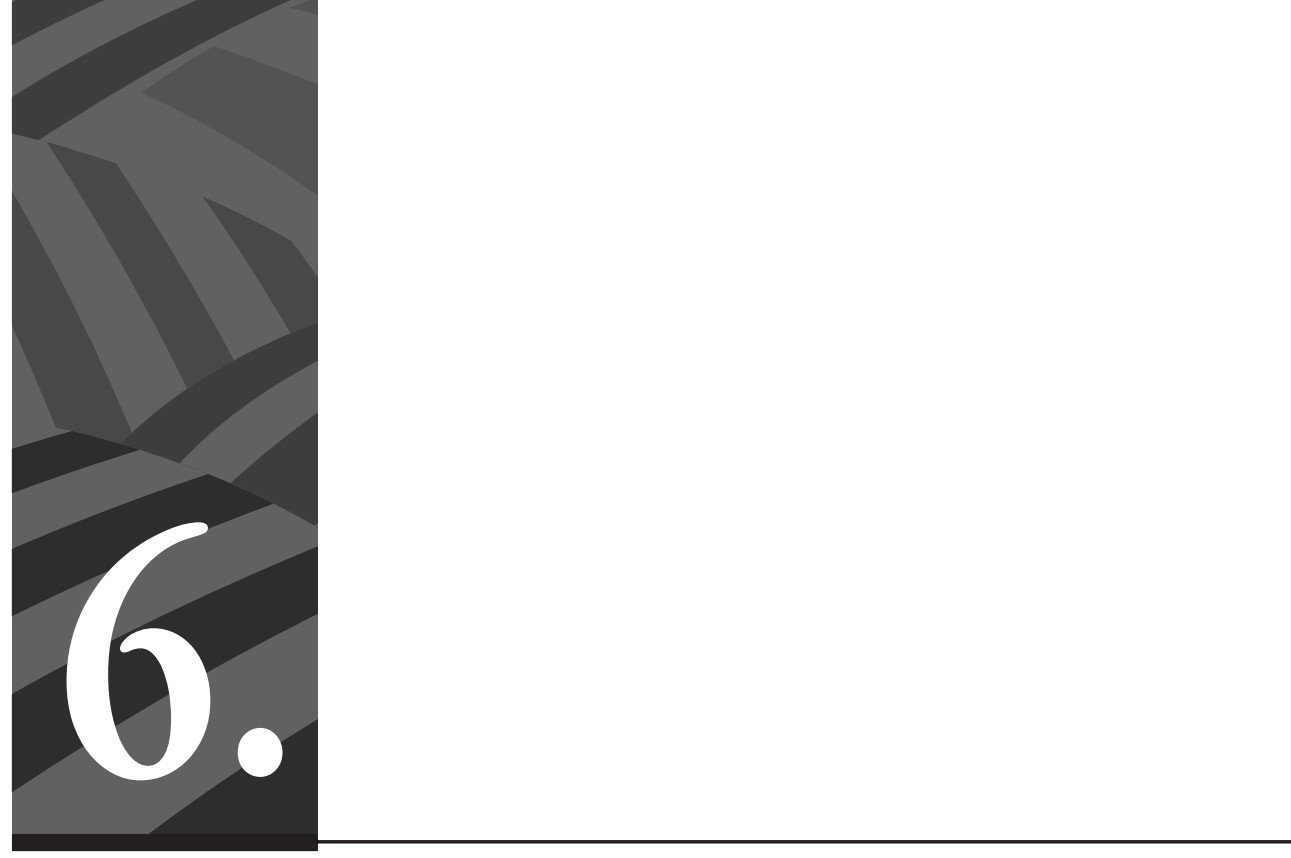

La movilización social en Colombia, un freno a la locomotora minera: el caso del páramo de Santurbán 


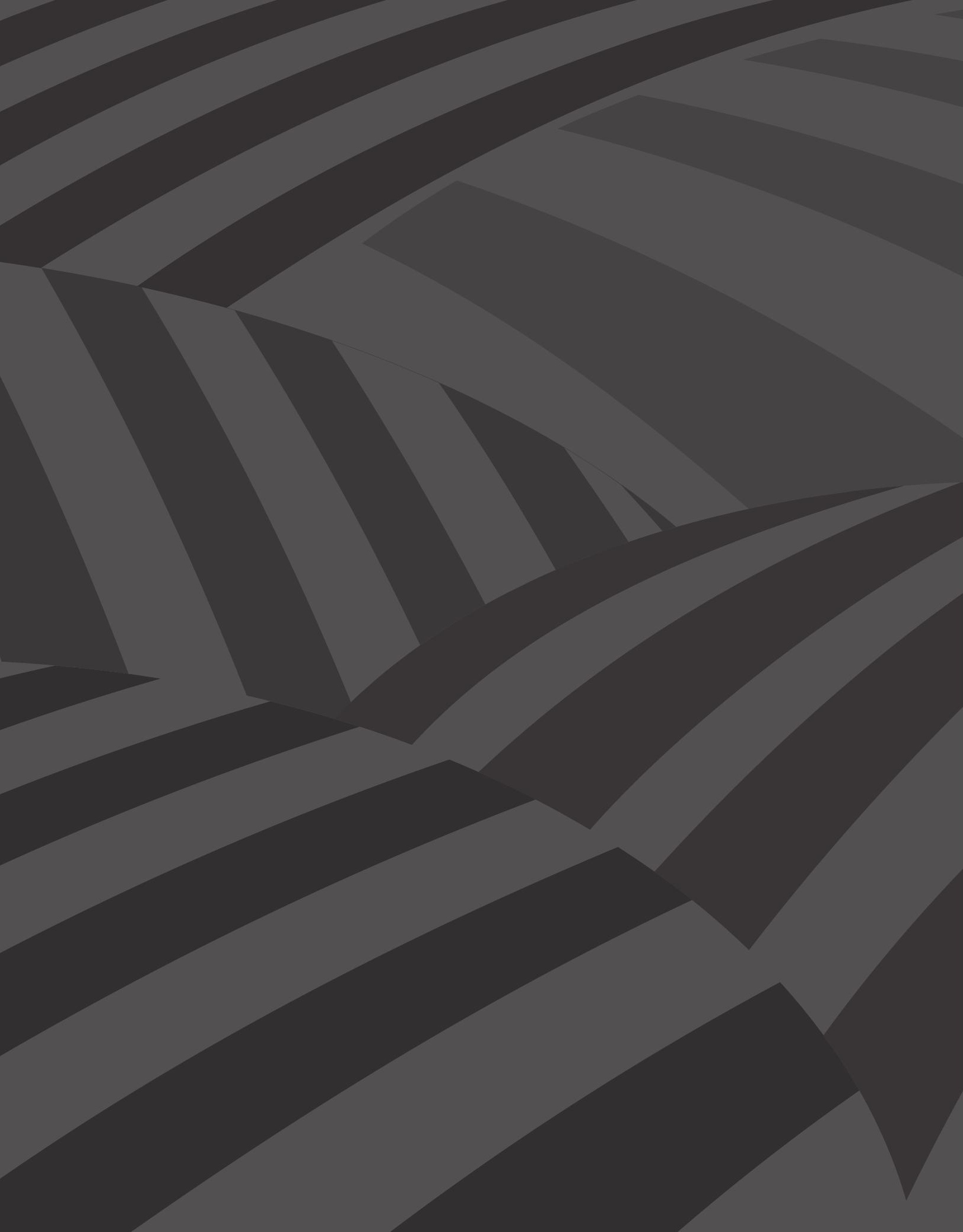




\section{La movilización social en Colombia, un freno a la locomotora minera: el caso del páramo de Santurbán}

Por Julie Paola Tibocha Avellaneda*

Resumen: Este trabajo reflexiona sobre el conflicto socioambiental sucedido en el 2011 en torno al proyecto de minería a cielo abierto Angostura, en Santander, con el objetivo de mostrar las dificultades y contradicciones que enfrentó el proceso de resistencia y organización social que logró que la empresa Greystar (hoy Eco Oro) retirara la solicitud de licencia ambiental y que se ordenara al Estado delimitar el Páramo de Santurbán. Para este fin se revisó la normatividad, así como textos académicos, entrevistas a los distintos actores y artículos periodísticos. Una de las principales conclusiones es que el ascenso de un Estado neoliberal que responsabiliza a la inversión extranjera del crecimiento económico y el progreso social, tiene como resultado el aumento de las desigualdades sociales y económicas, propicia el deterioro ambiental y produce fracturas en la sociedad civil, que al encontrar limitaciones para participar en los asuntos que la afectan, recurren a las movilizaciones masivas en las calles para presionar al Estado, frenar el mercado desregulado y visibilizar las demandas a toda la ciudadanía.

Palabras clave: Conflicto socioambiental, neoliberalismo, movimientos sociales, minería, Inversión Extranjera.

\section{The social mobilization in Colombia, a brake to the mining locomotive: the case of the Santurban's paramo}

Abstract: This paper recovers the socio-environmental conflict happened in 2011 around the Project of opencast mining Angostura in Santander, with the object of show the obstacles,

* Julie Paola Tibocha Avellaneda es administradora pública, egresada de la Escuela Superior de Administración Pública (ESAP). Cursó y aprobó las asignaturas de la maestría de Políticas Públicas para el desarrollo con inclusión social en FLACSO (Argentina). Actualmente, su trabajo de investigación está enfocado en temas del desarrollo económico, especialmente, la contribución de la minería y la capacidad del Estado para guiar esta actividad. Con este enfoque participó como finalista en el concurso para jóvenes investigadores de economía Por venir, organizado en 2017 por el Centro Estratégico Latinoamericano de Geopolítica, en Caracas, Venezuela. Correo electrónico: julietibocha@gmail.com 
dificulties and contradictions that faced the process of resistance and social organization which managed that the Company Greystar (Today Eco Oro) retire the request of environmental license and that it be ordered to the State delimits the Saturban's Paramo. For this end it was revised normativity, academic texts, interviews with the different actors and newspaper articles. One of the principals conclussions is that the ascent of a neoliberal State that blames to the foreign investment of the economic growth and social progress results in the increase in social and economics inequalities, propitiates environmental deterioration and produces fractures in civil society that when encountering limitatios for participate in matters that affect it, resort to the massive mobilizations in the streets as a way to put pression on the State, stop the deregulated market and visibilize the demands to the rest of citizens.

Keywords: Socio-environmental conflict, neoliberalism, social movements, mining, Foreign Investment.

Cómo citar este artículo: Tibocha Avellaneda, Julie Paola (2019). La movilización social en Colombia, un freno a la locomotora minera: el caso del páramo de Santurbán. Revista Controversia, 212, 177-203.

Fecha de recepción: 15 de noviembre de 2018

Fecha de aprobación: 15 de febrero de 2019

\section{Introducción}
n América Latina el auge del modelo neoliberal durante la década 4 de los noventa estuvo acompañado y fortalecido por una crisis de Megitimidad de las instituciones y del sistema político, que propul- só a la sociedad civil a adquirir nuevas responsabilidades y a aparecer en la esfera pública de nuevas formas.

En Colombia, la Constitución Política de 1991 es la expresión normativa y la condensación de las dimensiones de este modelo, pues consagró la democracia colombiana como representativa y participativa y, al mismo tiempo, promovió el predominio del mercado y el rol pasivo del Estado.

En este marco, la inversión extranjera en actividades extractivas ha sido alentada, dándole un lugar protagónico a las transnacionales mineras y favoreciéndolas con bajas regalías y reducciones tributarias, esto, a su vez, apoyado en la idea de que a través de la libre inversión se consigue 
crecimiento económico que se extiende de manera positiva a la sociedad en su conjunto.

El objetivo fundamental de este escrito es identificar la manera en la que participa la sociedad civil en Colombia y las tensiones que se generan con las empresas privadas multinacionales en un modelo extractivo liberal. Para el cumplimiento de este propósito, se analizará el conflicto socioambiental del páramo de Santurbán (Santander), describiendo los instrumentos y las formas de participación utilizadas por la ciudadanía frente a la intención de Greystar de ampliar la zona minera en el territorio.

Este caso fue emblemático porque mostró los alcances de la movilización social en el país, puso en cuestión el modelo económico y político impuesto por el Estado neoliberal y develó los intereses de la inversión extranjera en la explotación de recursos naturales. Este trabajo no solo es un ejercicio de memoria, además, pretende establecer un marco para comprender este conflicto socioambiental y, de esta manera, brindar herramientas para conocer sus coordenadas: un Estado subordinado a los intereses de las transnacionales, gobiernos carentes de voluntad política para delimitar el páramo, asedio económico y social a las comunidades de los municipios mineros, un renovado movimiento ambientalista y una multinacional que no piensa irse con las manos vacías

Para ello, en primer lugar, será importante explicitar la relación entre el Estado y la sociedad colombiana y, a partir de ahí, situar el conflicto en el marco del extractivismo minero de corte liberal y tradicional. En segundo lugar, se explicará cómo la multinacional Greystar (hoy EcoOro) logró posicionarse en el territorio como actor fundamental del crecimiento económico y desarrollo social. Posteriormente, se describirán las fases, contradicciones, dificultades y logros de la lucha social en contra del proyecto minero Angostura. Finalmente, se presentarán las repercusiones, el estado actual del conflicto y las conclusiones. 


\section{Tensiones y aciertos en la relación Estado-sociedad en Colombia}

El regreso o fortalecimiento de la democracia en América Latina a finales del siglo XX buscaba recuperar la legitimidad del Estado y fortalecer las instituciones. Esta tendencia que colocaba a los partidos como canalizadores de las demandas sociales, fortalecía el presidencialismo y enaltecía la sociedad civil; al mismo tiempo, imponía la idea de ingobernabilidad por exceso de demandas sociales, lo que se traducía en una reducción de los Estados a través de la disminución del gasto público y las privatizaciones. De esta manera, en la región el regreso de la democracia estuvo acompañado de la implementación del neoliberalismo.

En Colombia, este fortalecimiento democrático neoliberal inició con la asamblea nacional constituyente de 1991 que puso fin al Frente Nacional $^{1}$ y promulgó una nueva constitución política. Esta constitución garantizó nuevos derechos sociales y otorgó protagonismo a la sociedad civil por medio de la creación de mecanismos de participación, lo que implicó un cambio de la noción misma de ciudadanía: «en cierta medida se aleja un tanto de la noción de ciudadano individual, y [...] la ciudadanía se ejerce mediante la afiliación a organizaciones» (Faletto, 1989, p. 82). A su vez, permitió la participación del sector privado en áreas que antes eran de exclusividad del sector público (salud y educación).

Aprovechando este nuevo marco normativo, el gobierno de César Gaviria impulsó la apertura comercial y una política social basada en los siguientes principios: la focalización del gasto hacia los sectores de menores ingresos, la preferencia de subsidios a la demanda sobre los que se concentran en subsanar la oferta, la delegación de funciones de

1 El Frente Nacional fue un pacto firmado desde finales de la década de los 50 del siglo XX entre los partidos tradicionales (liberal y conservador) para "alternarse en el ejercicio del gobierno, repartirse milimétricamente el aparato estatal y excluir a cualquier otro actor político de la contienda electoral y de la posibilidad de conducir los destinos del país» (Velásquez y González, 2003, p. 43). 
prestación de servicios al sector privado y las que continúen en el sector público se descentralizan en entidades regionales o locales (Ocampo, 2004). En consonancia con Faletto (1989), este modelo permite la asignación de recursos por parte del mercado, reproduce la desigualdad social y, al desplazar al Estado de su función redistributiva, la situación de los sectores menos favorecidos se ve afectada negativamente.

En este contexto, la expansión de la cultura democrática junto con la cultura participativa condujo al surgimiento de nuevos movimientos sociales y a la desidentificación de la sociedad con las clases sociales y con los partidos políticos. La aparición de movimientos sociales con intereses específicos, vinculados a un grupo social, y otros con un interés colectivo que compete a la humanidad en su conjunto (De Sousa Santos, 2001), son un rasgo distintivo de este fenómeno.

Así, en la esfera pública colombiana, a partir de los años noventa, aparecen los pobladores urbanos como un nuevo actor y las luchas sociales se diversifican en torno a temas como incumplimientos de leyes y pactos, respeto a los derechos humanos y el derecho internacional humanitario (DHI), cuestionamiento a la autoridad y debates políticos, incluido el conflicto armado, todo ello sumado a las manifestaciones ya existentes sobre salario, empleo, servicios públicos, entre otros (Archila, 2006).

En el informe Luchas sociales en Colombia, del Centro de Investigación y Educación Popular/Programa por la Paz, se muestra que en el año 2013 los pobladores urbanos son los protagonistas del $32 \%$ de las luchas en el país, seguidos por los trabajadores asalariados (17 \%), los estudiantes (13\%) y los trabajadores independientes (11 \%); así, se evidencia la heterogeneidad de los actores. En cuanto a los motivos de las luchas, el $19 \%$ de ellas estuvo vinculada a políticas públicas, el $16 \%$ a los servicios sociales y dos cuartas partes a derechos integrales e incumplimiento de pactos y leyes (Cinep/PPP, 2014). Esto como evidencia de la suma de demandas materiales asociadas a las condiciones de vida de la población y las nuevas demandas. 
En correspondencia con la idea sostenida por Garretón (2001), según la cual los Estados neoliberales tienden a ceder tareas económicas y sociales, pero paradójicamente aumentan su capacidad coercitiva, el Estado Colombiano, presionado por un conflicto armado interno que le disputa el ejercicio del poder político y el dominio legítimo de la fuerza, aumenta su poder coercitivo de forma directa en unas partes del territorio y en otras de manera indirecta, cediendo ante los poderes regionales y negociando con estos para ejercer control (Archila, 2006).

Así mismo, los gobiernos apoyados por los medios de comunicación han descalificado las protestas sociales, tildándolas de desproporcionadas o equiparándolas con una expresión de la subversión (Archila, 2006). Con estos argumentos se han deslegitimado las demandas y justificado respuestas que penalizan, dividen o ilegalizan la lucha social y dan lugar a «efectos tanto físicos — asesinatos, detenciones arbitrarias, desplazamientos y exilio de dirigentes y activistas sociales y políticoscomo en el debilitamiento de las organizaciones sociales hasta doblegarlas o desaparecerlas, especialmente en las zonas de choque armado más agudo» (Archila, 2006, p. 22).

Paralelamente a la acción coercitiva, el Estado enaltece la participación de la sociedad civil cuando esta se articula y organiza en torno a intereses particulares, atiende sus propias demandas y reduce sus responsabilidades sociales por medio de acciones voluntarias y organizaciones no gubernamentales (ONG). Al respecto, Nogueira señala que en el marco del Estado liberal

las energías sociales corren de lado a lado, pero no se alimentan recíprocamente. Hieren a los gobiernos en un número mayor de puntos, pero no llegan propiamente a acorralarlos. Incluso, muchas veces son manipuladas por ellos. La dispersión de los movimientos ayuda a que apenas rodeen e irriten al Estado. La dinámica general no es anti-sistémica. (2003, p. 10)

A su vez, Nuria Cunill (2010) identifica que el control social ejercido por la ciudadanía en Colombia está reducido a los poderes indirectos 
que remiten al derecho a reclamar derechos ante una autoridad específica, materializados en acciones como el derecho de petición, la acción popular, la acción de amparo y la acción de cumplimiento, en los que la ciudadanía ejerce un control ex post sobre la administración. En contraposición, el poder directo para sancionar o modificar las formas de operación del Estado es limitado.

En síntesis, la sociedad civil en Colombia fue exaltada desde los años noventa en espacios de cooperación, gerencia de crisis e implementación de políticas (Nogueira, 2003), para lo cual la Constitución Política de Colombia dispuso de instrumentos de participación y control que han sido canalizados hacia ejercicios ex post mediados por instancias judiciales. Esta forma de concebir el rol de la sociedad civil ha generado fracturas entre las expectativas de las comunidades y lo que efectivamente obtiene. Por lo cual, y a pesar de la respuesta coercitiva del Estado, en los últimos años las movilizaciones sociales han sido relevantes por su duración, diversidad de actores, cobertura geográfica y porque han logrado revertir o afectar las decisiones de los gobiernos.

\section{Extractivismo liberal y conflicto social}

Como lo expone Svampa (2008), en la primera década del siglo XXI el neoliberalismo en la región se caracterizó por otorgar un papel central a las matrices extractivo-exportadoras como palancas del desarrollo. Si bien los gobiernos denotados como populares, progresistas o como la nueva izquierda ${ }^{2}$ también explotaron y exportaron recursos naturales (especialmente minería e hidrocarburos), lo hicieron con una fundamentación distinta a la liberal, lo que dio origen a una diferenciación conceptual entre extractivismo y neoextractivismo.

2 Brasil con Luis Ignacio Lula da Silva, en Argentina con Néstor Kirchner y Cristina Fernández de Kirchner, en Venezuela con Hugo Chávez, en Ecuador con Rafael Correa y en Bolivia con Evo Morales. Gudynas (2009) integra también en este grupo a Chile con Michelle Bachelet y a Paraguay con Fernando Lugo. 
En el denominado neoextractivismo el Estado toma un papel más activo representado en la imposición de normatividad a los actores que hacen parte del sector minero o petrolero; la redistribución de las regalías, la negociación de nuevas tarifas y la aparición o aumento de impuestos; un papel más significativo de las empresas estatales visible en su participación, nacionalización o creación; y una mayor negociación con países del este asiático (Gudynas, 2009).

En contraposición, el neoliberalismo mantuvo un extractivismo tradicional, caracterizado por un Estado mínimo que da vía libre al mercado, a través de una regulación laboral y ambiental laxa, y la liberación de flujos de capital, trayendo consigo la expansión indiscriminada de las corporaciones transnacionales mineras (Gudynas, 2009).

Como lo sostiene Svampa (2008), el extractivismo liberal, pese a sostener argumentos ecoeficiencistas ${ }^{3}$, intensifica los conflictos socioambientales, muy presentes en la megaminería a cielo abierto que se instaura como «una suerte de modelo descarnado, en el cual las más crudas lógicas de la expropiación económica y la depredación ambiental se combinan con escenarios grotescos, caracterizados por una gran asimetría de poderes, que parecen evocar la lucha desigual entre David y Goliat» (p.17). Las transnacionales son el David que impone un discurso productivista y se asientan en territorios marcados por la pobreza y la vulnerabilidad social que responden con revalorización del territorio y oposición a estos proyectos (Goliats).

En este marco, la contaminación del agua, la tierra o el aire, sus consecuencias sobre la salud y la escasez de agua potable; problemas territoriales; ausencia de participación y consulta de las comunidades

3 El ecoficientismo postula «el eficiente uso de los recursos naturales y el control de la contaminación. Sus conceptos clave son "modernización ecológica”, "desarrollo sustentable" y, de manera más reciente, "industrias limpias", entre otras» (Svampa, 2008, p. 6). 
afectadas; la violación a los derechos humanos y el incumplimiento de políticas de responsabilidad corporativa social de las transnacionales, se han convertido en los motivos más comunes que impulsan la movilización social y el surgimiento de nuevos movimientos sociales (SaadeHazin, 2013).

Estos nuevos movimientos sociales se caracterizan porque: inician con una demanda puntual, pero tienden a ampliar y radicalizar su discurso cuestionando el modelo de desarrollo y la mercantilización de los medios comunes; una revalorización de la relación de las comunidades campesinas e indígenas y la tierra/territorio; utilizan acciones directas disruptivas y no convencionales junto con acciones institucionales; generan espacios deliberativos con ejercicios de democracia directa; llaman a la autodeterminación; comprenden la multiescalaridad, pues se involucran distintos actores - estatales, productivos, sociales- en diferentes niveles - local, nacional, transnacional- (Svampa, 2008).

En paralelo, y como estrategia de contención por parte de las empresas transnacionales (respaldadas por los Estados neoliberales), aparece el concepto de Responsabilidad Social Empresarial (RSE) que apunta a «combinar la filantropía empresarial con una idea más general acerca de la responsabilidad de las empresas respecto del impacto social y ambiental que generan sus actividades» (Svampa, 2008, p. 17). Amparadas en la RSE las empresas ampliaron su influencia en las comunidades locales que, como lo sugiere Svampa (2008), apunta a comprar las voluntades y a afectar los procesos de socialización.

\section{Conflictividad socioambiental alrededor de la minería en Colombia}

En el 2001, con la aprobación del código minero, se le dio sustento normativo al extractivismo liberal en Colombia. A través de esta nueva reglamentación se abrió la puerta a la gran minería y se reestructuró el 
reparto de la renta minera disminuyendo regalías, impuestos y obligaciones de reparación social y ambiental.

Este contexto normativo, político y económico da cabida a planes nacionales y sectoriales como el Plan Nacional de Desarrollo Minero 2007-2010, que presenta como actores fundamentales de la minería a los inversionistas y a los empresarios u operadores de los proyectos mineros, a su vez, responsables del crecimiento económico y, desde la responsabilidad social empresarial (RSE), también de mejoras sociales. De igual manera, el Plan Nacional de Desarrollo «Prosperidad para todos» 2010-2014 situó a la minería como una de las locomotoras de desarrollo por medio de la cual se conseguirían mejoras en términos sociales y productivos.

En cuanto a la RSE, esta se ha promovido como acciones voluntarias de las empresas privadas para mejorar las condiciones de vida de los habitantes de los territorios afectados por la actividad minera. Al ser voluntarias no implican contraprestaciones o deducciones por parte del Estado; sin embargo, en la práctica los programas de RSE responden a intereses comerciales y mediáticos de las multinacionales y, al ser ejecutados por fundaciones de las mismas empresas, estas terminan siendo beneficiadas con deducciones impositivas (Pardo, 2014). Por esta vía el Estado deja de captar recursos y colabora con el mantenimiento de la buena imagen de las multinacionales, sin que esto conlleve necesariamente a progresos en la calidad de vida los habitantes.

En el país, según el informe Minería en Colombia: control público, memoria y justicia socio-ecológica, movimientos sociales y posconflicto, desde la década de los 80 hasta el 2013 se han presentado 72 conflictos socioambientales, de estos 30 tienen que ver con minería, la mayoría de los cuales se relacionan con la minería del oro (Morelli, 2014).

Los movimientos campesinos han sido actores fundamentales de estos conflictos y han utilizado mecanismos de participación como la consulta 
y la iniciativa popular para confrontar o frenar los proyectos mineros liderados por las transnacionales (Roa, 2018). Sin embargo, y debido a las limitaciones a la participación directa, cuando estas acciones ponen en jaque el modelo, son bloqueadas por el Estado, como en el 2017, cuando se negó el financiamiento de consultas populares.

Así, contrario a las expectativas puestas en la actividad minera, los territorios en los cuales se asientan las empresas extractivas presentan altos niveles de pobreza e inequidad según los indicadores de desarrollo humano ${ }^{4}$. Esto tiene correspondencia con las demandas exigidas en los conflictos vinculados a la extracción minera y petrolera, en las que, como lo indica el Cinep/PPP (2012), predominan las asociadas a temáticas laborales y al respeto a los derechos económicos y sociales. De este modo, el comportamiento de la locomotora minera conecta temas como derechos humanos, derechos laborales, distribución de la riqueza, salud pública y temas medioambientales.

Este trabajo se enfoca en un caso emblemático de resistencia social: la oposición al proyecto minero Angostura en el nororiente del departamento de Santander, Colombia, durante el 2011, en defensa del páramo de Santurbán. Este conflicto puso en evidencia la atmósfera conflictiva, la acción del Estado, el agotamiento de los mecanismos de participación indirectos y los intereses de las multinacionales.

\section{Estructura metodológica}

Esta investigación utilizó una estrategia cualitativa para dilucidar las motivaciones, contradicciones, obstáculos y logros de la movilización social en oposición a la ampliación de la zona minera en Santander, durante

4 Con excepción de Antioquia, todos los departamentos mineros presentan índices de pobreza altos. Al respecto Saade Hazim (2013) sentencia «todos los departamentos muestran niveles de pobreza mayores al promedio nacional $(34,1)$. [...] El Chocó, Córdoba, La Guajira, César y Bolívar ocupan los lugares número 1, 3, 5, 9 y 10, respectivamente en orden de mayor pobreza en Colombia» (p. 26). 
el 2011. Lo anterior, remitiendo a la evolución y al escalonamiento del conflicto a partir de las disputas y acuerdos entre los involucrados.

La unidad de análisis está constituida por los actores involucrados (estatales a nivel departamental, municipal y nacional; movimientos ambientalistas; población de los municipios mineros; empresa transnacional Greystar).

Para la recolección de datos se utilizaron fuentes secundarias, tales como: prensa, entrevistas, informes, estudios y documentos oficiales.

La estrategia de análisis fue la sistematización de los datos teniendo en cuenta los actores involucrados y las dimensiones de análisis establecidas en el marco teórico: nuevos movimientos sociales, posición dominante de las transnacionales en el marco del extractivismo liberal y limitaciones de los mecanismos de participación en el Estado neoliberal.

\section{Un pacto de oro entre el Estado y Greystar}

Los municipios de Veta y California, ubicados en el departamento de Santander, son los territorios donde nace este conflicto alrededor del agua. Estos dos municipios han estado históricamente ligados a la actividad extractiva minera; al principio de manera artesanal y posteriormente a gran escala debido al retorno de la empresa canadiense Greystar al territorio en 2003 y a las barreras de entrada impuestas a los pequeños mineros.

Greystar realizó su actividad ininterrumpidamente desde 1995 hasta el 2000. Los territorios en cuestión estaban abandonados por el Estado y controlados por la FARC, grupo armado que encontró en las actividades extractivas otra fuente de financiamiento ${ }^{5}$, por lo que mantenía

5 Previo al incremento del precio de las materias primas, se utilizaban métodos como vacunas, extorsiones y el secuestro de personas vinculadas a la minería legal, informal o ilegal (Pardo, 2013). 
relaciones y comunicaciones con la multinacional (Censat, 2009). En el 2000 la empresa abandona el territorio tras un episodio en el cual son secuestrados algunos de sus empresarios.

En el 2003, Greystar, impulsada por los beneficios establecidos por el código minero y las políticas del gobierno de Álvaro Uribe Vélez — de promoción a la inversión extranjera y de seguridad democrática一, vuelve a Santander y establece un arreglo implícito con el Estado, según el cual este último le garantizaba seguridad y un entorno propicio para invertir y, a cambio, la empresa se encargaría de la educación, los servicios públicos e infraestructura. Así, se selló un pacto que implicó el retorno relativo del Estado, mediante presencia militar ${ }^{6}$, pero desentendiéndose de sus funciones sociales que quedan sujetas al voluntarismo de Greystar.

Los proyectos de responsabilidad social ejecutados por Greystar (muchos a través de su fundación) respondieron a las necesidades económicas y mediáticas de la compañía. De modo que, se realizaron talleres de costura para elaborar los uniformes, servicios de alimentación para los empleados, capacitación de sus trabajadores, emisoras donadas por la empresa, entre otros (Censat, 2009). En paralelo, la actividad agrícola en Vetas y California se deterioró, la minería a pequeña escala se vio perjudicada, aumentó la dependencia de los proyectos desarrollados por la multinacional y, adicionalmente, los cuerpos hídricos del departamento de Santander se expusieron al riesgo.

Sumado a esto, la presencia del ejército en la zona no eliminó o mitigó la violencia. De acuerdo al informe de la Defensoría del Pueblo del 2007, citado por Censat (2009), se han reportado asesinatos,

6 Según el Observatorio de Conflictos Mineros en América Latina (OCMAL) (2016), «Dentro del perímetro del proyecto de exploración Angostura, existen dos campamentos militares: un campamento habitado por cerca de 35 soldados en el sector Los Laches y un campamento habitado por 20 soldados en el sector Escuela». Adicionalmente, Greystar proporcionó apoyo logístico para establecer las bases militares (Censat, 2009). 
desplazamientos y amenazas, presuntamente ejecutadas por paramilitares. Como consecuencia el $40 \%$ de los 5000 habitantes del área está catalogada como población en alto riesgo. Esto estaría en concordancia con la investigación de Fernando Vargas Valencia (2013), en la que se muestra la relación entre el conflicto armado interno y la minería, y se saca a la luz un accionar común de las multinacionales que pactan con actores armados legales e ilegales para preparar el territorio, demarcar los proyectos, comprar terrenos con facilidad y eliminar la oposición.

Vale la pena recalcar que desde su retorno al territorio Greystar contó con el apoyo de varios actores estatales: en el 2006 el presidente Uribe le entregó al vicepresidente de la compañía un premio por el desempeño ambiental y social; en el 2004, el entonces gobernador de Santander, Hugo Naranjo ${ }^{7}$, declaró que la inversión de esta multinacional debía ser respaldada por autoridades locales y el Gobierno nacional; en el 2006, el entonces director de Ingeominas, Juan Villareal Toro, se declaró a favor del proyecto Angostura para aumentar la producción de oro del país. Actualmente Villareal es el representante legal del proyecto de exploración y explotación de oro Gramalote, realizado por las mineras Anglogold Ashanti y B2Gold Corp.

En este contexto, en 2010 Greystar anuncia su interés de dar comienzo al proyecto Angostura, un proyecto de explotación de oro a gran escala y a cielo abierto que afecta parte del ecosistema del páramo de Santurbán ${ }^{8}$, en Santander, bajo el supuesto de que en esta zona po-

7 Después de su mandato, Naranjo ha sido investigado y capturado por casos de corrupción y fue condenado por la Corte suprema de Justicia en el 2013 por nexos con el paramilitarismo.

8 El páramo de Santurbán está «localizado en la Cordillera Oriental de Colombia, por encima de la cota de los 3.000 msnm, según el Instituto de Investigaciones Alexander Von Humboldt, entre los departamentos de Santander y Norte de Santander, a 67 kilómetros de Bucaramanga. Tiene una extensión de 90.000 hectáreas, distribuidas entre los 3.000 y los $4.500 \mathrm{msnm}$, en los municipios de California, Vetas, Tona, Charta, Silos, Mutiscua y Cucutilla» (Flórez, 2012, p. 465), cuenta, además, con cinco quebradas, dos ríos y diez lagunas. 
dría haber 511000 onzas de oro y 2.3 millones de onzas de plata. La empresa canadiense contaba con los títulos mineros en el territorio y necesitaba de la Licencia Ambiental que le otorgaría la Autoridad Nacional de Licencias Ambientales (ANLA).

Los páramos, de acuerdo al artículo 34 del Código de Minas, son zonas excluidas de la actividad minera; sin embargo, el área del páramo de Santurbán, en el momento de la solicitud de licencia, no había sido delimitada por la autoridad competente, es decir, como lo expresó el medio periodístico la Silla Vacía (2011), Santurbán era un páramo por sus condiciones geológicas, pero jurídicamente no había sido declarado como tal. Vacío legal que dio pie al conflicto.

\section{El agua se la regalamos, el oro es nuestro}

Los sindicatos de mineros, empleados directos e indirectos y alcaldes municipales de California y Vetas aprobaban el Proyecto Angostura. La consigna que manejaron durante todo el conflicto fue «el agua se la regalamos, el oro es nuestro». Esta posición se sostenía en los empleos e inversiones que había generado la multinacional y los que el proyecto Angostura les permitiría seguir generando. Es importante recalcar que, en años anteriores, en los municipios se había generado oposición a la multinacional ${ }^{9}$; sin embargo, esta posición se fue haciendo minoritaria debido al desgaste de la pequeña minería, al desplazamiento de la población y a las situaciones de riesgo ante el ejercicio de violencia armada en los territorios.

9 En el 2005, 300 habitantes habían firmado una carta de indignación frente a un artículo publicado por El Tiempo en el que se alababa a Greystar, entre otras cosas, expresaron: «se dice que el vuelco en la vida de los californianos se debe a la multinacional. Eso es lo único que tal vez es cierto en lo que expresa el periodista, pero en otro sentido: éramos una comunidad pacífica, tranquila hasta cuando llegó la gran empresa. Después llegaron los grupos armados, tras sus cuantiosos recursos. Igualmente se asegura que se acabó el desempleo en esta población donde a duras penas se sobrevivía de la agricultura por lo poco fértil de sus tierras. En California, el 90 por ciento de las mujeres en edad productiva están desempleadas» (El Tiempo, 2005). 
En aquel momento la empresa generaba entre 500 y 600 empleos directos (OCMAL, 2016) y aspiraba crear 870 empleos directos y 3400 indirectos (La Silla Vacía, 2011). Según el Plan de desarrollo municipal de California (2008-2011) la explotación minera ocupa el 54.4 \% del total de la población empleada, mientras que el municipio de Vetas sigue perdiendo población por la ausencia de opciones de empleo distintas a la minería que ocupa el 51 \% de la población.

Esta dependencia está antecedida por la venta masiva de los propietarios de títulos mineros a la multinacional, propiciado por el código minero que equiparaba «la capacidad de las grandes empresas mineras, rodeados de ventajosos abogados mineros y millonarios recursos económicos, con la de los pequeños mineros para acceder a un título minero, significando en la práctica la vigencia de un modelo excluyente que aportó también conflictividad al sector» (Pardo, 2013, p. 153). En concordancia, el alcalde de California manifestaba que el Estado había ahogado a los pequeños y medianos mineros por medio de las exigencias ambientales (Osorio, 2011).

En varias ocasiones, los habitantes y las autoridades de los municipios señalaron, en las audiencias y entrevistas, el abandono del Estado nacional y el desconocimiento de los ciudadanos de las zonas urbanas a sus modos de vida. En su tesis de maestría, Rodrigo Hurtado (2011) recoge algunas de estas declaraciones; por ejemplo, un representante político de la zona manifestó: «Los ambientalistas no conocen y solo ahora vienen a saber que existimos. Antes no sabían nada y con todas las necesidades que tenía nuestro pueblo» (Hurtado, 2011, p. 71). Por su parte, el alcalde de Veta, en la primera audiencia pública realizada sobre la licencia ambiental, declaró: «Los que recogen firmas en Bucaramanga pero nunca han pisado este suelo y hacen esas campañas contra nosotros» (Hurtado, 2011, p. 82), refiriéndose al movimiento ambientalista que recogía firmas en contra del proyecto en la capital del departamento. 
En el 2012 los sindicatos mineros se movilizaron en contra de la delimitación del páramo, puesto que no se estaba teniendo en cuenta la dependencia de los habitantes de los municipios a esta actividad y la tradición minera (Revista Dinero, 2012). En el pliego de peticiones presentado en el 2013 los mineros exigían al Gobierno nacional y departamental «Que se garantice la estabilidad, continuidad y sostenibilidad socioeconómica laboral de los trabajadores de la industria minera que comprende: pequeños mineros, medianos y minería a gran escala, bajo el marco de todas las garantías sindicales y el derecho fundamental al trabajo» (Vanguardia, 2013).

Sumado a esto, representantes de organizaciones sociales, líderes comunitarios y el sindicato minero, mediante derecho de petición, manifestaron al Ministerio de Ambiente los siguientes hechos: 1. La falta de seguridad jurídica del proyecto minero aumentó la tasa de desempleo; 2. Producto de esta situación, los trabajadores se han manifestado mediante marchas, plantones y audiencias públicas; 3. Pérdida de capacidad adquisitiva de la población. Con esta exposición de motivos solicitaron dar vía libre al proyecto de Angostura por considerarse de interés local y excluir a la zona minera en la delimitación del Páramo.

Esto generó un clima de tensión entre los habitantes de los municipios mineros y los movimientos socioambientales de la ciudad de Bucaramanga. En el rastreo de este conflicto se identifican las fuerzas que fragmentaron a la sociedad civil entre ambientalistas y mineros: la acumulación de títulos mineros por parte de Greystar, el posicionamiento de la empresa como fuente de bienestar producto del abandono estatal, la dependencia a la minería como generadora de empleo, el desplazamiento y el ahogo de otras actividades en el territorio. Como lo expresa Nogueira: «una sociedad civil fragmentada fragiliza las bases de contestación, bloquea la democracia e incentiva la improductividad de los gobiernos» (2003, p. 5). En efecto, el Ministerio de Ambiente suspendió la audiencia pública bajo el argumento de «batalla entre las partes». 
Retomando las ideas de Nogueira, la sociedad civil de los municipios Vetas y California ejemplifica la postura antiestatal propia del neoliberalismo desde la cual se desconfía del Estado, se glorifica al mercado y se actúa colectivamente para obtener ventajas o extraer mayores dividendos para sí. Esto no invalida sus demandas y, de acuerdo con Font (2003), deben evaluarse de manera respetuosa, dado que «cuanto más exijamos de energías, mayor riego podrá existir de una participación poco representativa, y que cualquier esfuerzo deberá tener en consideración los límites de la información habitualmente disponible» (p. 27).

\section{La movilización social como freno de la locomotora minera}

Inicialmente la oposición al proyecto estuvo liderada por el movimiento ambientalista y en el transcurso del conflicto se fueron sumando diversos actores sociales. La consigna recuperaba la importancia del agua frente a la minería dentro del departamento de Santander, es decir, recuperando las ideas de Boaventura De Sousa Santos (2001), se basaba más en reclamos alrededor de la cultura y la calidad de vida que de la riqueza y el bienestar material. De acuerdo con el mismo autor, este tipo de movimientos van más allá de la concesión de derechos y ponen en cuestión el modelo de desarrollo.

El criterio que mantenía vinculados a los opositores al proyecto y que logró aglutinar a la comunidad fue que los ríos que nacían y se alimentaban del páramo nutrían el acueducto para proveer del servicio de agua potable a los municipios del departamento. Si bien el movimiento ambientalista, desde el año 2000, venía advirtiendo sobre la afectación de la minería al paisaje, la fauna y la flora del Páramo, fue con las declaraciones del gerente del acueducto metropolitano, en las que se advertía de los costos que requeriría purificar el agua y el efecto sobre las tarifas del servicio, que la causa recibió un apoyo masivo por parte de la población (Flórez, 2012).

En esta lucha social la sociedad civil recurrió a mecanismos de participación como las audiencias públicas ambientales y la movilización 
social, mientras que las universidades y gremios empresariales organizaron foros de debate acerca de la minería a cielo abierto.

Las audiencias públicas ambientales son mecanismos deliberativos que permiten una interacción entre la administración y los ciudadanos y que tiene como finalidad

dar a conocer a las organizaciones sociales, comunidad en general, entidades públicas y privadas la solicitud de licencias, permisos o concesiones ambientales, o la existencia de un proyecto, obra o actividad, los impactos que este pueda generar o genere y las medidas de manejo propuestas o implementadas para prevenir, mitigar, corregir y/o compensar dichos impactos; así como recibir opiniones, informaciones y documentos que aporte la comunidad y demás entidades públicas o privadas. (Decreto 330, 2007)

Este tipo de instrumentos ponen su énfasis en la reflexión y el diálogo de los ciudadanos comunes (Font, 2003) y buscan la obtención de información que será tenida en cuenta en la toma de decisiones por parte de la autoridad ambiental.

Según la normatividad, las audiencias públicas pueden ser solicitadas por el procurador general de la Nación o el delegado para asuntos ambientales y agrarios, el defensor del Pueblo, el ministro de Ambiente, Vivienda y Desarrollo Territorial, los directores generales de las demás autoridades ambientales, los gobernadores, los alcaldes o por lo menos cien (100) personas o tres (3) entidades sin ánimo de lucro (Decreto 330 , 2007). Para el caso en cuestión, la audiencia fue solicitada por el comité en defensa del agua y el páramo de Santurbán que agrupaba a líderes comunitarios y ambientalistas, organizaciones estudiantiles, docentes, ONG, representantes de partidos políticos, respaldados, además, por más de las cien personas requeridas por la norma.

Dentro del proceso se realizaron dos audiencias públicas; la primera fallida porque no contó con la presencia de la parte opositora al proyecto 
y la segunda suspendida por la autoridad ambiental, por las razones enunciadas párrafos atrás. Este mecanismo de participación no es integral en los términos considerados por Sergio de Piero (2010) y Nuria Cunill (2010) puesto que no tiene una incidencia directa en las decisiones de la autoridad ambiental.

Conscientes de la debilidad de este instrumento, la sociedad se movilizó en las calles cuatro veces entre 2010 y 2011. La movilización más significativa fue la última marcha, del 25 de febrero del 2011, denominada como la «Gran Marcha». Aunque las estimaciones sobre la cantidad de asistentes varía según la fuente, varios coinciden en que fueron más de 30000 santandereanos los que se manifestaron en contra del proyecto Angostura. En Bogotá, Cartagena, Cúcuta y Pamplona también se realizaron marchas en apoyo a la movilización social de Santander y en oposición a la locomotora minera.

\section{Alcances y repercusiones ambientales, sociales y económicas}

La movilización social alrededor del páramo de Santurbán logró que la empresa retirara la solicitud de licencia ambiental y llevo a que cambiara su nombre a Eco-Oro como una estrategia para limpiar su imagen y continuar con su actividad económica.

El Ministerio de Ambiente, por medio de la Resolución 1015 del 2011, no acepta el desistimiento de Greystar y niega la licencia ambiental. En esta expresa que la autoridad ambiental pública no puede ser ajena a las manifestaciones sociales, reconociendo que estas son

la expresión de la ciudadanía, la cual, como se ha indicado en los fundamentos legales de este acto administrativo, tiene el derecho constitucional a participar en las decisiones que los afectan, y siendo Colombia un Estado social de derecho, organizado en forma de República democrática, participativa y pluralista, fundada en el respeto de la dignidad humana, en la 
solidaridad de las personas que la integran y en la prevalencia del interés general, ha de darse mérito y crédito a las manifestaciones mayoritarias de la comunidad en la toma de la decisión. (MinAmbiente, Resolución 1015, 2011)

En el 2014, por medio de la resolución 2090, se delimitó geográficamente el páramo de Santurbán, sin tener en cuenta las comunidades afectadas y excluyendo de la delimitación 30000 hectáreas de páramo (que coinciden con las zonas de títulos mineros). Por esto, en el 2017 la Corte Constitucional declaró la nulidad y dio un año al Estado para pronunciarse de nuevo (Paz y Latam, 2018).

Tras estos estos traspiés, Eco-Oro ha decidido demandar al Estado colombiano, dando a entender que cuando desistió de la solicitud de licencia ambiental, no había renunciado a la explotación del páramo, sino que estaba esperando la nueva delimitación. Sin embargo, ahora que este conflicto se prolongó y se insta a la participación de la sociedad civil, sale a relucir el interés de la multinacional, que es obtener el máximo redito económico y devolverlo a su casa matriz en Canadá.

\section{Conclusiones}

Este caso sentó un precedente para la defensa de los páramos y los movimientos sociales en Colombia en varios sentidos: demostró que estos proyectos son inviables sin la aprobación social, lo que avivó la discusión sobre la licencia social; obligó al Estado a delimitar el área geográfica de los páramos y a prohibir en definitiva la explotación minera en estos ecosistemas; reafirmó la potencialidad de la movilización y la protesta en las calles, dando cauce a otras manifestaciones dentro del territorio en contra de la minería a cielo abierto liderada por trasnacionales.

Las expresiones de la sociedad civil en Colombia, en el marco de un modelo neoliberal, se presentan de formas contradictorias. Por un lado, las fuerzas fragmentadoras propias del modelo y las desigualdades sociales y económicas propiciadas por un Estado ausente y un mercado 
desregulado han despolitizado algunos sectores de la sociedad civil y han generado movilizaciones dirigidas a valorizar los intereses de las trasnacionales extractivistas presentes en el territorio. Sin embargo, esto no agota las formas de expresión de la sociedad y, a pesar de los riesgos de la lucha social en el país, los nuevos movimientos sociales, cuando logran visibilizar sus demandas como de interés público, alteran las decisiones de las autoridades estatales.

Ante la ineficacia de los mecanismos de participación formales en Colombia, indirectos y ex post, la sociedad civil recurre a la protesta en las calles como una forma de presionar al Estado y visibilizar las problemáticas. El número de luchas, la diversidad de actores y el conjunto de demandas, evidencian las inconformidades y el poder de la sociedad civil. Las luchas sociales, al ser momentáneas y circunstanciales, no logran modificar el sistema, pero sí logran cuestionarlo.

En este conflicto, aún no resuelto, es necesario atender las necesidades de la población de Vetas y California que -debido al abandono del Estado (luego por su regreso relativo) y la dependencia laboral a Eco Oro- han visto vulnerados sus derechos políticos, sociales y económicos. Esto exige un rol activo del Estado, un fortalecimiento de los mecanismos de participación directos y, en últimas, una reconfiguración del modelo económico y político que permita el mejoramiento de sus condiciones de vida, su reorganización y autonomía.

\section{Referencias}

Alcaldía de California (2008-2011). Plan de Desarrollo 2008-2011: California Para Todos. California.

Archila-Neira, Mauricio (2006). Los movimientos sociales y las paradojas de la democracia en Colombia. Revista Controversia, 186, 10-32. Recuperado de https://bit.ly/2MpVHP2.

CENSAT Agua Viva y MiningWatch Canadá (septiembre, 2009). Tierras y Conflicto. Extracción de recursos, derechos humanos y la responsabilidad social empresarial: compañias canadienses en Colombia [Informe]. Ottawa, Ontario, Canadá: Interpares. 
Centro de investigación y Educación Popular-Programa Por la Paz [Cinep/PPP] (2012). Minería, Conflictos Sociales y Violación de Derechos Humanos en Colombia. Bogotá: Cinep/PPP.

Centro de investigación y Educación Popular-Programa Por la Paz [Cinep/PPP] (2014). Luchas sociales en Colombia:2013. Bogotá: Cinep/PPP.

Cunill, Nubia (2010). El Control Social en América Latina. Fondo de Control Social: Ciudadanos al cuidado de lo público. Bogotá.

De Piero, Sergio (2010). Participación Ciudadana en Políticas Públicas. Buenos Aires: Fundación Banco Provincia.

De Sousa Santos, Boaventura (2001). Los nuevos movimientos sociales. Debates, 177-188.

El Tiempo (18 de abril de 2005). California, Pueblo Indignado. El Tiempo.

Faletto, Enzo (1989). La especificidad del Estado Latinoamericano. Revista de la CEPAL, 69-88.

Flórez Flórez, Mario (2012). En Defensa del Páramo de Sánturban. En Toro, Catalina; Fierro, Julio; Coronado, Sergio y Roa, Tatiana (Edits.), Mineria, Territorio y Conflicto en Colombia (pp. 465-484). Bogotá: Universidad Nacional de Colombia.

Font, Joan (2003). Participación ciudadana y decisiones públicas:conceptos, experiencias y metodologías. Seminario Internacional Participación ciudadana y políticas sociales en el espacio social (pp. 23-41). México: UNAM.

Garretón, Manuel (2001). Cambios sociales, actores y acción colectiva en América Latina. (CEPAL, Ed.) Políticas Sociales, 9-45.

Gudynas, Eduardo (2009). Diez tesis urgentes sobre el nuevo extractivismo: contextos y demandas bajo el progresismo sudamericano actual. En Schuldt, Jürgen; Acosta, Alberto; Barandiarán, Mauricio; Bebbington, Alejandra; Folchi, Mauricio; Alayza, Alejandra y Gudynas, Eduardo (Edits.), Extractivismo, política y sociedad (pp. 187-225). Quito: Centro Andino de Acción Popular [CAAP]-Centro Latinoamericano de Ecología social [CLAES].

Hurtado, Rodriguo (2011). La contienda política alrrededor de la licencia ambiental para el proyecto minero Angostura en el páramo de Santurbán [Tesis de maestría]. Bogotá: Universidad Javeriana. Recuperado de https:// bit.ly/2TJtC6i. 
La Silla Vacía (13 de marzo de 2011). Los poderes detrás del paramo de Santurbán . La Silla Vacia.

Ministerio del Medio Ambiente y Desarrollo Sostenible (31 de mayo de 2011). «Por la cual no se acepta un desistimiento por motivos de interés público, se niega una licencia ambiental global y se toman otras determinaciones.» Resolución 1015 del 2011. Recuperado de https://bit.ly/31QeJlu.

Ministerio de Ambiente, vivienda y desarrollo territorial (8 de febrero de 2007). Decreto 330.

Morelli Rico, Sandra (2014). Minería en Colombia: Control público, memoria y justicia socio-ecológica, movimientos sociales y posconflicto. Bogotá: Contraloría General de la República.

Nogueira, Marco (2003). La sociedad civil como campo de luchas, como recurso gerencial y como espacio ético. Reforma y Democracía, 1-15.

Ocampo, José (2004). Entre las reformas y el Conflicto: Economía Política en Colombia. Bogotá: Norma.

Observatorio de Conflictos Mieros de América Latina [OCMAL] (marzo, 2016). Proyecto Angostura: amenaza la biodiversidad del Páramo de Santurbán. OCMAL. Recuperado de http://www.conflictosmineros.net/.

Osorio, Camila ( 9 de marzo de 2011). Los poderes detrás del páramo de Santurbán. La Silla Vacía.

Pardo Becerra, Luis (2013). La conflictividad por el territorio, el control de los RNNR y la renta minera: El choque de las locomotoras mineras en Colombia. En Garay, Jorge (ed.), Mineria en Colombia: Institucionalidad y territorio, paradojas y conflictos (pp. 143-192). Bogotá: Contraloría General de la República.

Pardo Becerra, Luis (2014). Una política integral minera desde la perspectiva de un sistema complejo: hacia un modelo alternativo. En Garay, Luis (dir.), Minería en Colombia: Daños ecológicos y socioeconómicos y consideraciones sobre un modelo minero alternativo (pp. 31-79). Bogotá: Contraloria General de la República.

Paz, Antonio y Latam, Mongabay (27 de abril de 2018). El enorme problema para delimitar el páramo de Santurbán. Semana Sostenible. 
Revista Dinero (26 de noviembre del 2012). Mineros de Santurbán marcharan en Bogotá. Revista Dinero. Recuperado de https://bit.ly/2z4Ouv5.

Roa Avendaño, Tatiana (2018). Colombia: participación democrática en la toma de decisiones ante proyectos extractivos y el reclamo por los derechos campesinos. En. Álvarez, Laura y Godfrid, julieta (comps.) Megaminería en América Latina: Estados, empresas transnacionales y conflictos socioambientales (pp. 229-252). Ciudad Autónoma de Buenos Aires: Centro Cultural de la Cooperación Floreal Gorini; Universidad Nacional de Quilmes.

Saade Hazin, Miryam (2013). Desarrollo Minero y conflictos socioambientales. Los casos de Colombia, México y el Perú. Santiago de Chile: CEPAL-ONU.

Svampa, Maristella (2008). La disputa por el desarrollo: territorios, movimientos de carácter socio-ambiental y Discursos dominantes. En Svampa, Maristella, Cambio de época. Movimientos sociales y poder político. Buenos Aires: Siglo XXI.

Vanguardia (2 de septiembre de 2013). Mineros de Vetas y California lograron acuerdos con el gobernador de Santander. Vanguardia. Recuperado de https://bit.ly/2ZfE5rr.

Vargas Valencia, Fernando (2013). Minería, conflicto armado y despojo de tierras: impactos, desafíos y posibles solucioes jurídicas. En Garay, Luis (dir.), Minería en Colombia: Derechos, Políticas Públicas y Gobernanza (pp. 5788). Bogotá: Contraloría General de la República.

Velásquez, Fabio y González, Esperanza (2003). ¿Qué ha pasado con la participación ciudadana en Colombia? Bogotá: Fundación Corona. 